\title{
KÜLTÜREL BAĞLAMDA RUS VE TÜRK KÜLTÜRÜNDE DİNI BAYRAMLAR
}

\author{
RELİGIOUS HOLIDAYS İN RUSSİAN AND TURKISH CULTURE FROM A \\ CULTURAL PERSPECTIVE
}

\section{РЕЛИГИОЗНЫЕ ПРАЗДНИКИ В РУССКОЙ И ТУРЕЦКОЙ КУЛЬТУРЫ С ТОЧКИ ЗРЕНИЯ КУЛЬТУРЫ ${ }^{1}$}

\section{Muhammed TAŞKESENLIGIIL*}

\section{ÖZ}

Kültür, bir milletin ortak yaşam tarzıdır. Kültürün en önemli unsurları, gelenek, görenek ve inançlardır. Her milletin sahip olduğu gelenek, görenek ve inançların sosyal yaşama yansıyan yüzü ise bayramlardır.

Dini bayramlar yılın belli bir gününde ve belli bir takvime bağlı olarak kutlanır. Bu özelliklerinden hareketle, kaynağını topluluk hayatından alan dini bayramlar, kolektif bir olgudur.

$\mathrm{Bu}$ makalede ilk olarak dini bayramların Rus ve Türk kültüründeki önemine değineceğiz. Daha sonra her iki ülkede yılın belirli dönemlerinde kutlanan bu dini bayramları karşılaştırmalı olarak anlatacağız. Türk kültüründe en önemli dini bayramlar olan Ramazan ve Kurban bayramını ve kandil gecelerinin önemine değinip Rusya'daki Noel, Paskalya, Maslenitsa gibi önemli dini bayramlardan bahsedeceğiz.

Anahtar Sözcükler: Rus ve Türk Kültürü, Dini bayramlar, Hıristiyanlık, İslam İnancı

\section{ABSTRACT}

Culture is a nation's public life. The most important elements of culture are traditions, customs and beliefs. Festivals are the reflection face of social life that every nation's traditions, customs and belief.

Religious holidays are celebrated on a certain day of the year and according to a schedule. Because of these properties, religious festivals which takes its source from public life is a collective phenomenon.

In this article firstly we will discuss the importance of religious holidays in Turkish and Russian culture. Then we will explain comparatively these religious festivals celebrated in certain periods of the year in both countries. Referring to the importance of the most important religious holidays of Muslim Ramadan, Feast of sacrifices and Muslim holiday

${ }^{1}$ DOI : 10.17498/kdeniz.919

* Kafkas Üniversitesi Slav Dilleri ve Edebiyatları Bölümü Rus Dili ve Edebiyatı Anabilim Dalı Arş. Gör.m_taskesenli@hotmail.com 
nights in Turkish culture we will talk about the most important religious holidays in Russia such as Christmas, Easter and Maslenitsa.

Key words: Religious festivals, Culture, Christian holidays, Christmass, Easter,

\section{Аннотация}

Культура является общественной жизни нации. Наиболее важными элементами культуры являются традиции, обычаи и верования. Фестивали являются отражением лицом общественной жизни, что каждый народ по традиции, обычаи и верования.

Религиозные праздники отмечаются в определенный день года и в соответствии с графиком. Из-за этих свойств, религиозные праздники, которые берет свое начало от общественной жизни является коллективным явлением.

В этой статье во-первых, мы будем обсуждать важность религиозных праздников в турецкой и русской культуры. После этого мы будем объяснять сравнительно эти религиозные праздники праздновали в определенные периоды года в обеих странах. Ссылаясь на важность наиболее важных религиозных праздников мусульманского Рамадана, праздник жертвоприношения и мусульманский праздник ночей в турецкой культуре мы будем говорить о самых важных религиозных праздников в России, таких как Рождество, Пасха и Масленицы.

Ключевые слова: Религиозные праздники, культура, христианские праздники, Рождество, Пасха

\section{Giriş}

Dini bayramlar, yeryüzünde yaşayan çeşitli dinlere mensup toplulukların belli bir tarihte, yılda bir kere bir veya birkaç gün sevinç gösterileriyle ve ayinlerle, ritüellerle kutladığı günlerdir.

Dini bayramlar, toplum yapısında gördüğü işlevlere göre "birleştirici, canlandırıcı, eğitici ve mutluluk verici” olmak üzere dört başlık altında toplanabilir:

1. Birleştirici İşlev: Fertleri bir araya getirir. Toplum üyeleri arasındaki dayanışma bağlarını güçlendirip, ortak değerleri pekiştirir. Topluluğun dağınık yaşayan üyelerini bir araya getirir, topluluğun birliğini sağlar.

2. Canlandırıcı İşlev: Toplumda canlandırıcı, geleneklerin devamını sağlayıcı, inançları tazeleyici ve bu yolla değer yargılarının, törelerin köklenmesine yardım edici özelliği vardır.

3. Eğitici İşlev: Bütün dini bayramlar, fertleri toplum hayatında, toplumun gerekli kıldığı düzen bağını ve ortak değerleri paylaşma gereğini öğreterek eğitirler.

4. Mutluluk Verici (Rahatlatıcı) İşlev: Bütün dini bayramlar, kutlayanlarına toplumun bir üyesi olma mutluluğunu kazandırır. Kutlamalar, insanları birlikte eğlenerek baskıdan, gerilimden kurtarır. Bireysel yalnızlıkların ortadan kaldırılmasının yanı sıra, çaresizliklerin azaltılmasına ve giderilmesine firsat verir.

Türk halk kültüründe dini bayramlar denilince akla gelen ilk isimler Ramazan ve Kurban Bayramlarıdır. Dini bayramların zamanları, güneş takvimine göre değil de, ay takvimine bağlı olarak hesaplandığından, güneş takvimine göre düzenlenmiş olan hayatımızda her yıl aynı günlere rastlanmaz. İki takvim sistemi arasında on gün fark vardır 
ve bu yüzden dini bayramlar, her yıl bir öncekine göre on gün daha önce kutlanılır. Ramazan Bayramı üç gün boyunca Kurban Bayramı ise dört gün süresince kutlanır. Türk halk kültüründe bayram kutlamaları resmi tatil günleridir. Bayram kutlama geleneğimizde bu iki bayram kadar olmasa da çeşitli biçimlerde kutlanan bazı özel dini günler vardır. $\mathrm{Bu}$ tür özel dini günlerin başında Mevlid, Miraç, Beraat, Kadir Gecesi gibi kandil günleri, Şebi Aruz Gecesi ve Ayin-i Cem gibi çeşitli törenler gelir.

Her dinde olduğu gibi, evrensel bir din olan Hıristiyanlıkta da çeşitli dini bayramlar bulunmaktadır. Ancak Hıristiyanlıktaki bu bayramlar, örneğin Yahudilikteki gibi doğrudan Kutsal Kitaba dayanmamaktadır. Bunun yerine bu bayramlar, bizzat Hiristiyanlar tarafından tarihi süreç içerisinde kademeli olarak ortaya konmuştur. Bu çerçevede, İsa'dan kısa bir süre sonra onun hayatındaki önemli olayları anmaya yönelik bazı kutlamalar ortaya çıkmaya başlamıştır. Önceleri sadece, İsa'nın hayatındaki çok önemli bir- iki olayı anmaya yönelik olarak başlatılan bu kutlamalar, sonraki yüzyıllarda gittikçe artarak İsa'nın hayatındaki hemen hemen her önemli olayı kapsar hale gelmiştir. Böylece günümüz Hıristiyan Kilisesinde İsa'yla ilgili olarak kutlanan bayramların tamamı, zaman içerisinde kademeli olarak ortaya çıkmıştır. Bu çerçevede İsa'nın doğumu, çarmıhta ölümü, dirilişi ve göğe yükselişi gibi olaylar Hıristiyanların hayatında gittikçe önem kazanarak her yıl düzenli biçimde kutlanmaya başlanmıştır. (Katar 2001: 8)

İsa'yla ilgili bu bayramların kutlanmaya başlanmasından bir süre sonra, Meryem Ana ve çeşitli Hıristiyan azizleriyle ilgili bayramlar ortaya çıkmaya başlamıştır. Önceleri oldukça az olan bu tür kutlamaların sayısı zamanla gittikçe çoğalmış ve bu artış günümüze kadar artarak devam etmiştir. Tarihi süreç içerisinde ortaya çıkan bu bayramların çok az bir kısmı Hıristiyan toplumunun ilk dönemlerine kadar uzanmakta, diğerlerinin ise daha sonraki yüzyıllarda, hatta yakın dönemlerde ortaya çıktığı belirtilmektedir. Hıristiyan Kilisesi bu bayramları kutlayarak Hıristiyan toplumunun, İsa'yı takip eden bu seçkin insanları kendilerine örnek şahsiyetler olarak almalarını sağlamaya çalışmaktadır." (Katar 2001: 9)

Rusya'da Hıristiyan kilisesinin dini yıl anlayışı içerisinde İsa'yla ilgili kutlanan bu bayramların ilki, İsa'nın Dirilişi (Рождества Христова, Nativitiy of Christ) yani Paskalya bayramıdır. Paskalya, Hıristiyanlıktaki en eski ve en önemli bayramdır. İsa'nın çarmıha gerildikten sonra 3. günde dirilişi kutlanır.

Doğu ve Batı kiliseleri arasında farklılıklar olmakla beraber, Paskalya dönemi yaklaşık olarak Mart sonundan Nisan sonuna kadar olan dönemdir. Her sene sabit bir tarihte gerçekleşmeyen ve dünya kiliselerinin çoğunda Pazar günü kutlanan Paskalya günü Kıyam Yortusu, Diriliş Pazarı ya da Diriliş Günü olarak da adlandırılır. Paskalya'nın yanı sıra Rusya'da her yıl farklı zaman dilimlerinde kutlanan diğer dini bayramlar da şunlardır: Hz. İsa’nın Dirilişi Bayramı (Рождество Христово, Christmas Day) Paskalya Bayramı (Пасха праздник, Easter feast) Palmiye Pazarı Bayramı (Вербное Воскресение, Palm Sunday), Paskalya Öncesi Perşembe ya da Büyük Perşembe Bayramı (Чистый Четверг, Maundy Thursday), Hz. İsa'nın Göğe Yükselişi Bayramı (Вознесение Иисуса Христа на небо) Meryem Ana'nın Göğe Alınması Bayramı (Вознесение Девы Марии, Ascension of Virgin Mary), Maslenitsa (Масленица).

Rus kültürü ve Türk kültüründeki dini bayramlara ve bu bayramların önemine kısaca değinmeye çalıştık. Makalemizin bundan sonraki bölümlerinde ise Rus ve Türk kültüründe çok önemli bir yere sahip olan dini bayramların özelliklerini ve bu bayramların toplumlar için taşıdıkları değerleri anlatmaya çalışacağız. 


\section{Rus Kültüründe Dini Bayramlar}

\subsection{Hz. İsa'nın Dirilişi Bayramı (Рождество Христово, Christmas day)}

Hıristiyan kilisesinin dini yıl anlayışı içerisinde İsa'yla ilgili kutlanan bu bayramların ilki Noel ve Noel' e hazırlık mahiyetindeki Advent dönemidir. Advent, Latince "varma, gelme, geliş" anlamlarına gelen "adventus" tan gelmektedir. Terim olarak ise Adventin iki anlamı bulunmaktadır: Bunlardan birincisi, İsa'nın yaklaşan doğum gününü bekleyiş, onun doğumuna hazırlanma; ikincisi ise İsa'nın kurtarıcı ve yargılayıcı olarak büyük bir kudretle ahir zamanda tekrar gelişini ifade etmektedir. İsa'nın doğumuna manen hazırlanmak için teşkil edilen Advent dönemi, Noel tarihinden önceki dördüncü Pazar gününde başlamaktadır. Bu dönem aynı zamanda Kilise takviminin de başlangıcını oluşturmaktadır. Advent dönemi, Noel'e kadar uzanmakta ve daima dört Pazardan oluşan bir süreyi ihtiva etmektedir. Başlangıç günü tam sabit olmayan bu devrenin ilk günü, yani Advent Pazarı, 27 Kasım ile 3 Aralık arasındaki yedi günlük tarihten birine rastlamaktadır. ( Sullivan 1985: 199) Advent dönemini, İsa'nın doğumunun kutlanması olan Noel takip etmektedir. Eskiden Noel kutlamalarına büyük önem verilmekte ve her Hıristiyan'ın bu uygulamalara katılması gerekli görülmekteydi. Bu amaçla Ortaçağda oldukça ayrıntılı törenler icra edilmekteydi. $\mathrm{Bu}$ çerçevede, İsa'nın doğum gününden önceki gün oruç tutulmakta, İsa'nın doğum anı olarak kabul edilen gece yarısı çeşitli dua ve ilahilerle beklenmekteydi. ( Sullivan 1985: 205)

Günümüzde ise Noel kutlamaları eski öneminden çok şey kaybetmiştir. Artık birçok Hıristiyan İsa'nın doğum günü öncesinde oruç tutmamakta ve onun doğum anını beklemeye yönelik gece ayinine katılmamaktadır. Bu bağlamda Katolik Kilisesi de eskinin katı uygulamalarında değişiklikler yapmış ve örneğin İsa'nın doğum gününden önce tutulan oruç uygulamasını kaldırmıştır. Bu orucun yerine ise Noel arifesinde riayet edilen kısa süreli bir perhiz konmuştur. Dolayısıyla, günümüzde İsa'nın doğumunu kutlamak amaciyla yapılan uygulamaların çoğu, sadece birer gelenek şeklinde devam etmektedir. Bu gelenekler çerçevesinde Noel gününde güzel kıyafetler giyilmekte, pahalı dekorasyonlar kullanılmakta, sunaklar binlerce 1şıkla 1şıklandırılmaktadır. (Sullivan 1985: 205-206)

\subsection{Paskalya Bayramı (Пасха праздник, Easter feast)}

Hıristiyanlıkta Hz. İsa'nın çarmıha gerilerek öldürüldükten sonra yeniden dirilişi inancıyla ilişkili bir bayramdır. Hıristiyanlığın ortaya çıkışıyla birlikte "pascha" Hz. İsa'nın insanlığın günahı için kendini feda ederek çarmıhta öldürülmesi ve sonra yeniden dirilmesi inancıyla özdeşleştirilmiş ve bunun anısına yapılan kutlamayı ifade etmeye başlamıştır.

İsa'nın doğumu devresinde yapılan kutlamalardan sonra onun öldükten sonra dirilişi anısına yapılan Paskalya dönemi kutlamaları başlamaktadır. Paskalya devresi içerisinde yer alan bayramlar, ayın hareketlerine göre belirlendiği için bu bayramların başlangıç tarihleri her yıl değişmekte ve yeniden belirlenmektedir. (Katar 2001: 16)

$\mathrm{Bu}$ dönem içerisinde yer alan bayramlar Paskalyaya hazırlık devresi olan Lent dönemi ile Paskalya gününden sonra gelen elli günlük Paskalya devresi içerisinde kutlanmaktadır.

Lent; Kilisenin, insanların günahtan kurtulmak için özel bir faaliyet ve çaba göstermeye çağırdığı Paskalya öncesindeki kefaret dönemini ifade etmektedir. Bu dönem, baharda tabiatın kendisini yenilediği gibi, insanın da kendi hayatını daha güzel olana dönüştürme ve manen yenilenme çabasını sarf etmesi gereken kırk günlük bir oruç ve manevi arınma zamanı olarak kabul edilmiştir. Önceleri Hıristiyan adaylarını vaftize hazırlamak için teşkil edilmiş olan bu dönemin ana gayesi; insanın günahlardan arınarak Paskalyaya manen hazırlanmasını sağlamaktır. Bir pişmanlık ve nedamet devresi olan Lent döneminde, 
rahiplerin kıyafetleri, üzüntüyü sembolize etmek amacıyla bu dönemin üç hafta öncesinden başlayarak, pişmanlığın sembolü olan mor kıyafetlerle değiştirilir. ( Sullivan 1985: 210)

Hıristiyan geleneğinde Paskalya kutlamasının tam olarak ne zaman ortaya çıktığı bilinmemekle birlikte kaynaklarda Hıristiyanlığın ilk yüzyıllarından itibaren başladığı ve Milan Fermanı'na kadar Hıristiyanların yegâne önemli kutlamasını teşkil ettiği belirtilmektedir. http://www.fizan.net/paskalya.html (12.05.2014) Diyanet İslam Ansiklopedisi, cilt 34, s.181. Paskalya maddesi.

Buna göre en geç II. yüzyılın ilk yarısında Doğu kiliseleri tarafından benimsendikten sonra aynı yüzyılın ikinci yarısında Roma kilisesine geçmiştir.

Yeni Ahid'de, ilk Hıristiyan toplumunun, Yahudi anlayışına göre haftanın ilk gününü teşkil eden pazar gününü "Rabb'in günü" olarak adlandırdığına dair ifadeler mevcuttur. Bu çerçevede, muhtemelen Hz. İsa'dan kısa bir süre sonra bu yeni inancın mensuplarının İsa'nın diriliş günü olarak kabul ettikleri pazar gününde bir araya gelip onun son akşam yemeğini seremonik biçimde tekrarladıkları anlaşılmaktadır.

\subsection{Palmiye Pazarı Bayramı (Вербное Воскресение, Palm Sunday)}

İsa'yla ilgili bu törenler onun, Palm Sunday (Palmiye Pazarı) günü Kudüs'e büyük bir törenle girişinin anılmasıyla başlamaktadır. Bugün rahip ve maiyetindeki din adamları mabede girerken kilise korosu "Davud' un oğluna hosanna; Rabbin adıyla gelen mukaddes olsun. Ey İsrail kralı: yücedekine hosanna" şeklindeki ilahiyi okur.

İsa'nın Kudüs'e bu gelişinde halk, onu palmiye dallarını coşkuyla sallayarak karşıladığı için, bugün yapılan ayinlerde de palmiye ve zeytin dalları kullanılır. Rahip bu kutsamayı yaparken, sadece İsa'nın Kudüs'e girişindeki karşılama esnasında kullanılan palmiye dallarını değil, aynı zamanda Nuh Tufanı'nın sonunda güvercinin, tufanın bittiğinin ve Tanrı ile insan arasında yeni bir barışın tesis edildiğinin sembolü olarak Nuh'a getirdiği zeytin dalını da kutsadığını ifade eder. Kutsanan bu dallar cemaate dağıtılır ve bir tören alayı oluşturulur. Ayini yöneten rahipler ile koro mensuplarının da içinde bulunduğu bu tören alayı, sunağın tam karşısında yer alan batı kapısından çıkarak kilisenin kapısı önünde toplanır ve çeşitli ilahiler eşliğinde, İsa'nın Kudüs'e girişini temsil eder şekilde tekrar kiliseye girer. ( Sullivan 1985: 143-144)

\subsection{Büyük Perşembe Bayramı (Чисmыı̆ Четверг, Maundy Thursday)}

Maundy Thursday olarak adlandırılan Perşembe günü, İsa'nın çarmıh süreci öncesinde yapmış olduğu önemli bazı uygulamaların anıldığı ve tekrarlandığı bir günü oluşturmaktadır. "Kutsal" ya da "Büyük Perşembe" denilen bu Perşembe gününde İsa'nın on iki havarisiyle yediği son akşam yemeği ve bu yemek esnasında tesis ettiği evharistiya (Ekmek Şarap Ayini )için törenler icra edilmektedir. http://en.wikipedia.org/wiki/Maundy_Thursday (13.05.2014)

Kutsal Perşembe günü yapılan ayinde, özellikle ayinin başında Lent döneminin (Paskalya öncesindeki kefaret dönemi) geneline hakim olan keder ve matemin yerine, bir neşe ve coşku bulunmaktadır. Bugün için rahipler keder ve matem simgesi olan mor kıyafetler yerine neşe ve sevincin simgesi olan beyaz kıyafetlerini giyerler. Neşe ve sevincin sembolü olarak kabul edildikleri için Lent dönemi boyunca okunmayan "Gloria in Excelsis" (Yücelerde olan Tanrı'ya hamt olsun) ilahisi coşkuyla okunurken çanlar ve kilise orgu neşeyle çalınır. 


\section{5. İsa'nın Göğe Yükselişi Bayramı (Вознесение Иисуса Христа на небо, Feast} of the Ascension of Jesus)

İsa'nın göğe yükselişi, Hıristiyanlıkta İsa'nın Tanrının oğlu olarak babasının yanına geri çekilmesi olarak bilinir. Paskalya'dan 39 gün sonra, Paskalya orucundan ise 40 gün sonra kutlanır. $\mathrm{Bu}$ yüzden bu bayram daima Perşembe gününe denk gelir. $\mathrm{Bu}$ şekilde en erken 30 Nisan'da, en geç 3 Temmuz'da kutlanır. Hıristiyan öğretisindeki miraç günlerinden biridir. İsa'nın öldükten 3 gün sonra dirildiğine ve birçok insana göründükten sonra, 40.günde havarilere görünüp, göğe babasının yanına yükseldiğine inanılır. http://en.wikipedia.org/wiki/Ascension of Jesus (15.05.2014)

\subsection{Meryem Ananın Göğe Alınması Bayramı (Вознесение Девы Марии,} Ascension of Virgin Mary)

Hıristiyan Kilisesinin Meryem Ana ile ilgili kutlamalarından biri de Ağustos ayı içerisindeki "Meryem Ananın Göğe Alınması Bayramıdır." Katolik Kilisesinin, 1 Kasım 1950 yılında yaptığı açıklamaya göre Meryem'in bedeni, onun ölümünden sonra çürümekten korunmuş ve kısa bir süre sonra göğe alınarak ruhuyla bütünleşmiştir. Bu anlayışla Kilise, 15 Ağustos'u, Meryem'in göğe alınması bayramı olarak kutlamakta ve bu bayramı, Meryem'le ilgili en önemli kutlamalardan biri olarak kabul etmektedir. Bu nedenle de bu bayramda pek çok Hıristiyan ülkesinde, özellikle Meryem'le bir ilişkisi olduğuna inanılan, Fatima, Lourdes ve Efes gibi yerlerde çeşitli törenler yapılmaktadır. http://en.wikipedia.org/wiki/the ascension of virgin mary (15.05.2014)

\subsection{Maslenitsa (Масленица, Maslenitsa)}

Maslenitsa kavram işareti yağ anlamına gelen maslo kelimesinden türetilmiştir. Nitekim sözcük maslennaya (yağlı) sıfatına /-itsa/ ekinin getirilmesi ile ortaya çıkmıştır.

"Verimlilik Tanrısı Veles”le de ilgili olan Maslenitsa, kış mevsiminin bitip güneşin yüzünü göstermesi, yavaş yavaş baharın gelmesi, baharla birlikte her şeyin yenilenmesi, canlanması sebebiyle kutlanır. "Halk Bayramı" da denilen bu bayrama, Hıristiyanların Slavyen Halklar arasında kabul edilmesinden sonra, farklı bir kimlik kazandırılmış ve Hıristiyanlıkla ve Hz. İsa'nın yeniden doğuşuyla irtibatlandırılmıştır. (Alyılmaz 2009: 3031)

Maslenitsa, Ortodokslar'ın Büyük Oruçlar'1 öncesinde, Paskalya’ya 7 hafta kala, 3-9 Mart günleri arasında kutlanır ve her zaman pazartesi günü başlar. Uzun ve çetin geçen kış mevsimi yüzünden bunalan, yaşamları sıradanlaşan Ruslar, Maslenitsa'ya birkaç gün (bir hafta) kala olağanüstü bir hazırlık, gayret ve heyecan içinde görülürler. Soğukların tesirini yitirmeye; havaların yavaş yavaş ısınmaya yüz tuttuğu bugünlerde Rusların yaşadığı ortamla ve doğayla ilgisi de artmaya başlar. Onlara farklı milletlerden ve inanışlardan olmalarına rağmen uzun yıllar bir arada yaşayan komşuları da eşlik ederler. (Alyılmaz 2009: 31)

Maslenitsa bayramının her günün kendine göre bir adı vardır. Kökleri yüzyıllar öncesine dayanan bu bayramın ilk günü Pazartesi'nin adı "karşılama”dır. Bu günde bliniler yapılır ve fakirlere dağıtılır. Akraba ve komşulara ziyaretlere gidilir. Salı'nın adı "cilve"dir. Cilve gününde erkekler kızları kızaklarla kaymaya ve blini ziyafetine davet ederler. Tüm ülkede, iyi kaynanaların damatlarını blini ile beslediği Çarşamba'nın adı "ağzının tadını bilen" dir.

Perşembe "sefahat" günüdür. Bu gün neşe ve sofra ziyafetinin doruğuna ulaşıldığ1 gündür. Sofralar ev yapımı şarap ve votkalar ile donatılır. Yarışmalar düzenlenir. Çocuklar 
ve gençler çuçelo denilen samandan yapılan korkuluğu maniler ve şarkılar eşliğinde sokak sokak gezdirir. En güzel giysileri giydirilen çocuklar ev ev dolaşarak ev sahiplerine maniler söyler ve cömertliklerini överler.

Cuma "kaynana akşamı" dır. Bu sefer de damatlar kaynanalarına büyük bir hürmetle blini ikram eder. Cumartesi "görümceler günü"dür. Genç gelin bu günde görümcesini arkadaşları ve akrabaları ile birlikte akşam oturmasına davet eder. Bu misafirlik genç gelin için tam bir sınav niteliğindedir. Gelin ayrıca bu günde görümcesine hediye armağan etmek zorundadır. Pazar günü ise artık "uğurlama" günüdür. Kışın bitişini sembolize eden çuçelo yakılarak yılın bereketli geçmesi için külleri toprağın altına gömülür. Akşam akrabalar ailenin en büyüğünün evinde toplanır. $\mathrm{Bu}$ günde herkes birbirinden helallik alır, dargınlıklara son verilir. İnsanlar pazartesi gününe temiz bir kalp ve hafif bir ruhla başlamış olur.

\section{Türk Kültüründe Dini Bayramlar}

Dini bayramlar, insanların sosyal hayatını canlandırmakta, insanları bir araya getirmektedir. Uzak yakın tüm akrabalar, tanıdıklar ve komşular bayram vesilesi ile görüşüp bayramlaşır ve özlem giderirler. Dini bayramlarda çalışmaya ara verilir, resmi tatillerin olmasıyla birlikte insanlar yakınları, komşuları ile sosyal ilişki kurma, birlikte vakit geçirme imkânına sahip olurlar. İnsanlar bir araya gelerek bir yandan geleneklerini, örf-adetlerini yerine getirirken bir yandan da olumlu sosyal ilişkiler kurarak sosyalleşme ve toplumsal yaşama ilişkin katkılarda bulunurlar.

Dinî bayramların en önemli ortak noktası, "toplanma" ve "eğlenme" özelliğidir. Eğlence; Bu folklorun dört temel işlevinden biri olarak gelenekleri oluşturan, şekillendiren ve değiştiren özelliklere sahiptir. Dinî bayramlarda gerçekleştirilen geleneklerin de temel çıkış noktası eğlenmektir. Günümüzde dinî bayramlarda devam eden kutlama, bayramlaşma, ziyaret, anma ve oyun kavramlarının hepsi eğlence içeriklidir. Bu bayramlarda gerçekleştirilen eğlenceler o kadar etkilidir ki kimi yörelerde dinî bayramların ismi gerçekleştirilen kutlama ile birlikte anılmaktadır. Bu durumun en genel örneği, Ramazan Bayramı'nın Şeker Bayramı olarak adlandırılmasıdır. Bu bayramda çocukların hep birlikte ev ev gezerek şeker toplaması, gelen misafirlere şeker ve tatlı ikram edilmesi gibi gelenekler bayramın ikinci ismi hâline gelmiştir. (Yüksel 2011: 3-4)

Türk halk kültüründe dini bayramlar denilince akla ilk gelenler Ramazan ve Kurban Bayramlarıdır. Bunların yanı sıra önemli gün ve geceler de vardır. Bu önemli geceler Kandil Geceleri adını almaktadır. Cuma Günü de İslam inancında ve Türk kültüründe önemli bir gündür. Bu gün ve geceler vesilesiyle kardeşlik ve dayanışma duyguları pekişir ve sosyal yardımlaşma ve yakınlaşma artar. Makalemizin bundan sonraki kısmında Türk kültürü ve İslam inancındaki bu dini bayramların yanı sıra bu önemli gün ve geceler hakkında da önemli bilgiler vereceğiz.

\subsection{Ramazan Bayramı (Праздник Рамадан, Feast of Ramadan)}

Ramazan bayramı, bir aylık oruçtan sonra yeme-içmenin ve her türlü helal nimetten yararlanmanın mubah olduğu; Müslümanların eğlenip birbirlerini ziyaret ettikleri, hediyeleştikleri; çocukların, fakirlerin ve kimsesizlerin sadaka verilerek sevindirildiği; kısaca İslâmî kardeşliğin toplumun her kesiminde canlı olarak yaşandığı; bütün bunlarla birlikte Allah'a karşı da sorumluluklarının bilinciyle topluca namaz kılıp birbirine nasihat ettikleri sevinç günleridir. Ramazan bayramında yapılması vacip olan fitır sadakası vermek, bayram namazı kılmak gibi ibadetlerin yanında sünnet, müstehap olanları da vardır. Ramazan'ın ilk gününde oruç tutmak ise haramdır. 
Ramazan bayramı, Ramazan ayının sonunda kutlanan üç günlük bayramdır. Ramazan bayramının kutlanma nedeni, aynı ayda, topluca tutulan oruçların ve diğer ibadetlerin sonucunda elde ettiğimiz sevaplardır. Bu bayramda herkes birbirini kutlar, çocuklar en güzel şekilde giydirilir; yanaklarından öpülür; ceplerine harçlıklar konur; şeker ve çikolatalar ikram edilir. Büyükler de birbirine sarılır; küslükler unutulur; tatlıya bağlanır. http://www.dinibil.com/ dini bayramlar (15.05.2014)

\subsection{Kurban Bayramı (Праздник жертвы, Feast of sacrifices)}

Kutsal kitap Kur'an-1 Kerim'de yazan bilgilere göre ilk "kurban” tecrübesi Hz. İbrahim zamanına uzanmaktadır. Allah'a oğlu olması için yakaran Hz. İbrahim'in oğlu olması halinde onu Allah'a kurban edeceğini söylemesi üzerine kendisine yapılan büyük bir imtihan olarak karşımıza çıkmıştır. Nitekim Hz. İbrahim'in dilekleri kabul olur ve bir oğlu olur. Ahde vefa gösterip oğlunu Allah yolunda kurban etmek üzereyken kendisine Allah tarafından vahiy meleği Cebrail (a.s) ile birlikte bir koç gönderilir ve kendisine Allah yolunda oğlu yerine bu koçu kesmesi emredilir. Bu durum, Allah'a olan sevginin ve bağlılı̆̆ın bir işareti olarak kuşaktan kuşağa günümüze kadar gelmiştir.

Kurban kesmek, maddi gücü yerinde olan kişilere farz kılınmıştır. Bu vazife aslında toplumsal yardımlaşma seferberliğine bir çağrıdır. Kurban bayramı, maddi imkânsızlıklar yüzünden "et ve et ürünleri” ihtiyacını karşılayamayan kişiler için en azından senede bir kez bu ihtiyaçlarını karşılayabilmeleri adına iyi bir firsattır.

Toplumsal ve sosyal açıdan önemli bir yere sahip olan Kurban bayramında yoksul insanlara, muhtaç ve kimsesizlere yardım eli uzatılmak suretiyle, insanlık ve Müslümanlık görevleri de yerine getirilmiş olur.

\subsection{Kandil Geceleri (Мусульманских праздничных ночей, Muslim holiday nights)}

Bilindiği gibi hemen her toplumda gerek örfi gerekse dini yönlerden önemli sayılan günler, geceler ve aylar vardır. Bu zaman dilimlerinde, meydana geldiği varsayılan ya da gerçekten meydana gelmiş olan bir takım olaylar sebebiyle çeşitli törenler, kutlamalar veya yas törenleri yapıla gelmiştir. Dayandıkları olayların ve sebeplerin tarihi realitelere uygunlukları tam olarak tespit edilemeyip tartışılsa da, bu tür zaman dilimlerinin toplumların hayatında önemli birer ritüel haline geldikleri gerçektir. Bunlar ortak değerlere sahip toplulukların sosyal ve kültürel hayatlarını canlı tutan unsurlardır.

Ülkemizde kandil geceleri diye bilinen geceler; Rebiulevvel ayının on ikinci gecesi olan Mevlid, Recep ayının ilk cuma gecesi olan Regaib, yine Recep ayının yirmi yedinci gecesi olan Miraç, Şaban ayının on beşinci gecesi olan Berat ve Ramazan ayının yirmi yedinci gecesi olan Kadir Gecesidir. Bu geceler Osmanlılar döneminde II. Selim zamanından başlayarak, minarelerde kandiller yakılarak duyurulup kutlandığı için "Kandil" olarak anılmaya başlamıştır. (Bozkurt 2001:300) Kandillerle ilgili birçok gelenek oluşmuştur. Kandil helvası, kandil simidi, daha yeni dönemde çikolata ve şekerleme dağıtmak adet olmuştur. Kandil öncesi oruç tutmak da adetlerimiz arasında yer alır.

\subsubsection{Mevlid Kandili (Ночь рождения Мухаммеда, Night birth of Muhammad)}

Mevlid gecesi, İslam dininde önemli bir yere sahip olan bir gündür. Mevlid, Arapça kökenli bir kelimedir. Manası ise doğum zamanıdır. Yani Mevlit Kandili, Hz. Muhammed'in dünyaya teşrif ettiği gündür.

Peygamber Efendimizin doğumunu ve doğum gününde yaşananları anlatan yapıtlara da mevlid denir. Bilinen tarihe göre Peygamber Efendimiz Hicri 12 Rebiülevvel'de dünyaya gelmiştir. Ancak bizim kullandığımız takvimin miladi takvim olması itibariyle 
Peygamberimizin doğum tarihi 20 Nisan 571'dir. Peygamberimizin dünyaya geldiği gün, İslam dini için şerefli ve kıymetli bir gündür. Bu nedenle her 20 Nisanın geçtiği hafta, Kutlu doğum haftası olarak değerlendirilir. Ogünlerde Peygamber Efendimize mevlitler okunur, bilmeyenlere Peygamber Efendimiz anlatılır.

\subsubsection{Regaib Kandili}

Regâib Kandili, Hicri takvimin Recep ayının ilk Cuma gecesine denk gelen kandil gecesidir. Kökü "arzulamak, meyletmek" anlamlarına gelen Regaib sözcüğü Kuran'da geçmez. Bu geceye Regaib gecesi ismini melekler vermişlerdir. Bu kandilin İslam kültüründe diğer kandiller gibi önemli bir yeri vardır. Allah bu kutsal gecede inananlara türlü ikramlar sunar. Bu güne hürmet edenleri ve bu günü ibadetle geçirenleri günahlarından azat eder. Bu kutsal gecede edilen dualar kabul edilir, yapılan ibadetler ve iyilikler karş1lık bulur. http://www.turkcebilgi.com/ansiklopedi/ regaib kandili (16.05.2014)

\subsubsection{Miraç Kandili (ночь вознесения Мухаммеда, night ascension of Muhammad)}

Miraç, Arapçada merdiven, yukarı çıkmak, yükselmek anlamlarını dile getirir. İslam'da Hz. Peygamber'in göğe yükselerek Allah'ın huzuruna kabul edilmesi olayıdır. Olayın iki aşaması vardır: Birinci aşamada Hz. Muhammed, Mescid-i Haram'dan Kudüs'e götürülür. İkinci aşamayı ise Hz. Muhammed'in Allah'a yükselişi oluşturur. Miraç olarak anılan bu yükselme olayı Kur-an'da anılmaz, ama çok sayıdaki hadis bu olayı ayrıntılı bir şekilde anlatır. http://samil.ihya.org/ansiklopedi/mirac.html (16.05.2014)

Miraç olayının gerçekleştiği gece Müslümanlarca Kadir gecesinden sonra en kutsal gece sayılmış ve bu gecenin ibadetle ihyası gelenekleşmiştir. Osmanlılar döneminde, camiler kandillerle donatıldığı için Miraç kandili olarak anılan geceyi izleyen gün, cami ve tekkelerde Miraç olayını anlatan ve Miraciye adı verilen şiirlerin okunması dinleyenlere süt ikram edilmesi de bir gelenekti.

\subsubsection{Berat Kandili}

Berat Arapça berâet kelimesinin Türkçeleşmiş şeklidir. Berâet, "iki şey arasında ilişki olmaması; kişinin bir yükümlülükten kurtulması veya yükümlülüğünün bulunmaması” anlamına gelir. Şâbanın on beşinci gecesinde Müslümanların Allah'ın affı ve bağışlaması ile günah yükünden kurtulacağı umularak bu geceye Berat gecesi denmiştir. Berat gecesi için Arapça eserlerde "şabanın ortasındaki gece", "mübarek gece", "rahmet gecesi" manalarına gelen terkipler kullanılmaktadır. http://www.fizan.net/berat-gecesi.html Diyanet İslam Ansiklopedisi 2001: 475 (16.05.2014) Berat gecesi Müslümanlarca kutsal sayılmış, bu gecenin diğer gecelerden farklı bir şekilde geçirilmesi, bu gecede daha fazla ibadet edilmesi âdet halini almıştır.

\subsubsection{Kadir Gecesi (Ночь предопределения, night of predestination)}

Kadir Gecesi İslam inancında, Ramazanın 27. gecesi, Kuran'ın gökten yeryüzüne indirilmeğe başlandığı gecedir. O gece Kandil gecelerinden biridir. İslam inancına göre, Kadir gecesinde bir yıllık işler takdir edilir, meleklerle Cebrail o gece yeryüzüne inerler. O gecede yapılan ibadetler bin yıllık ibadetten üstün sayılır.

Müslümanlar, Kadir Gecesinde kaza namazlarını kılar, nafile ibadetler yapar; yaptıkları hata ve günahlarını düşünür; pişmanlık duyar ve tövbe ederler. Geceyi idrak edenler, birbirlerinin kandillerini kutlar, ihtiyaç sahibi kimselere yardımda bulunurlar. 


\subsubsection{Aşure Günü (День ашура, Day of ashura)}

Aşure Günü, Hicri senenin ilk ayı olan Muharrem ayının onuncu günüdür. Muharrem ayı, Kuran-1 kerimde kıymet verilen aylardan biridir. Aşure bu ayın en kıymetli günüdür. Allah, birçok duaları bugün kabul etmiştir. Hz. Adem'in tövbesinin kabulü, Nuh'un (a.s) gemisinin tufandan kurtulması, Yunus'un (a.s) balığın karnından çıkması Aşure günü olmuştur. İbrahim (a.s) Nemrud'un hazırlattığı ateşte o gün yanmadı. Aşure gününde İdris (a.s) diri olarak göğe çıkarıldı. Yakup (a.s) o gün oğlu Yusuf'a kavuştu ve gözleri açıldı. Eyüp (a.s) iyileşti, Musa (a.s) Kızıldeniz'den geçti fakat Firavun ve askerleri Kızıldeniz'de boğuldular. İsa (a.s)'ın doğumu, Yahudilerin elinden kurtulup göğe çıkarılması gibi hadiselerin tümü Aşure günü gerçekleşmiştir. İslam inancında bu önemli gün bir bayram havasında kutlanır. Evlerde aşure çorbası pişirilip komşulara dağıtılarak kardeşlik ve dayanışma bu vesileyle daha iyi pekişmiş olur. http://www.turkcebilgi.com/Rehber Ansiklopedisi (17.05.2014)

\subsubsection{Cuma Günü (Пятницฺа, Friday)}

Cuma günü, Müslümanların toplanma ve kaynaşma günleridir. İnsanların, kişisel işlerinin yoğunluğu nedeniyle birbirlerini görmekte zorlandıkları büyük şehirlerde, Cuma namazı buluşma ve kaynaşma için anlamlı bir neden olmaktadır. Bunun farkında olanlar; kişisel programlarını Cuma namazına göre ayarlar.

Cuma gününün kutsallığı konusunda Allah (c.c) şöyle buyurur: Ey iman edenler, Cuma günü namaz için ezan okunduğu zaman Allah'ı anmaya koşun. Alışverişi bırakın. Bilseniz bu sizin için daha iyidir. Namaz bitince yeryüzüne dağılın. Allah'ın lütfünden rızık isteyin. Allah'1 çok anın ki mutluluğa erişesiniz.(Cuma 9-10)

Cuma namazı; sosyal dayanışma ve kaynaşmaya, birlik ve beraberliğe, İslâmî bilgilenme ve bilinçlenmeye vesile olan bir ibadettir. İslam inancında Cuma günleri insanlar bir bayram coşkusu içerisinde olur. Camiye gitmeden önce güzel ve temiz elbiseler giyilir, güzel kokular sürülür, birbirini tanıyan tanımayan insanlar selamlaşır, hasbihal ederler. Cami çıkışı yoksul ve kimsesizler için yardım toplanır. Konu komşu öğle yemeklerinde bir araya gelir. Yüzlerde gülümseme hâkim olur, insanlar arasında dostane ilişkiler hasıl olur.

\section{Sonuç}

Araştırmanın bulgularına göre, teknolojik gelişmeler ve köyden şehirlere verilen göçün bayram geleneklerini olumsuz etkilemesine rağmen çoğu ailenin gerek bulundukları yerde gerekse göçtüğü ilçe ve köylere giderek bayramlarını geleneklerine uygun geçirdikleri, bu özel günlerde yakınların hediyeleştiği, akraba ve komşu ziyaretlerinde bulunarak olumlu insan ilişkilerinde bulundukları tespit edilmiştir.

Çalışmada elde edilen bulgulara göre, Rus ve Türk kültüründe insanların bu dini bayramları coşkuyla karşılamaları, birtakım ön hazırlıklar yapmaları, o güne özgü temiz ve şık kıyafetler giymeleri, ikram, bayram namazından sonra toplu bayramlaşma, şeker toplama, sosyal yardımlaşma, akraba ve dost ziyaretleri gibi birtakım olumlu ilişkilerin hem geleneklerin yaşatılmasına hem de sosyal yaşama olumlu katkılar sağladığı yönündedir.

Çalışmada ayrıca Rus ve Türk kültüründe dini bayramların insan ilişkilerini güçlendirmede etkili olduğu sonucuna varılmıştır. Bu özel günlerin manevi duyguların güçlenmesine, birlik, beraberlik ve kardeşlik bağlarının kuvvetlenmesine, yardımlaşma ruhunun artmasına, dargınlık, düşmanlık, çekişme ve ayrılıkların giderilmesine, akraba, komşu ve büyüklerin ziyaret edilmesine, kısacası her türlü insani ve ahlaki değerlerin 
kazanılmasına etki ettiği görülmüştür. İnsanlar arasındaki hediyeleşme, toplu yenen yemekler ve yapılan ikramlar sosyal yaşama ve bireylerin sosyalleşme sürecine olumlu katkılar sağlamıştır. Her iki kültürde de dini bayramların ve önemli gün ve gecelerin hem geleneklerin, örf ve adetlerin yaşatılması hem de insan ilişkileri konusundaki duyarlılığın gelişmesine katkı sağladığı ve toplumsal barış ve bireylerin sosyalleşme süreci üzerine olumlu etkiler yaptığı söylenebilir.

\section{KAYNAKÇA}

ALYILMAZ, Semra. Maslenitsa ve Nevruz Bayramları Arasındaki İlişki. (y.y.y) Uluslararası Sosyal Araştırmalar Dergisi, Volume 2/7 Spring 2009, 30-31

BOZKURT, Nebi. “Kandil”, Diyanet İslam Ansiklopedisi (DİA). İstanbul, 2001

GÜLŞAH, Yüksel. Dini Bayramları Kutlama Gelenekleri ve Bu Geleneklerin İnsan İlişkilerine Etkisi. (y.y.y) Uluslararası Hakemli Sosyal Bilimler E-Dergisi, Sayı: 26, EylülEkim 2011, 3-4

KATAR, Mehmet. Hıristiyan Bayramları Üzerine Bir Araştırma. (y.y.y) Dini Araştırmalar Dergisi, Ocak-Nisan, c.3, 2001, s.8

SULLIVAN, Watts. the Concise Oxford Dictionary of the Christian Church. London 1985, 562; Dictionary of Religions,.Edited by John R. Hinnells, G. Britain 1984

http://www.kulturelbellek.com/bayramlar ve törenler (10.05.2014)

http://www.fizan.net/paskalya.html Diyanet İslam Ansiklopedisi. (y.y.y) cilt 34, s.181. Paskalya maddesi. (12.05.2014)

http://en.wikipedia.org/wiki/Maundy_Thursday (13.05.2014)

http://en.wikipedia.org/wiki/Ascension_of_Jesus (15.05.2014)

http://en.wikipedia.org/wiki/the ascension of virgin mary (15.05.2014)

http://www.dinibil.com/ dini bayramlar (15.05.2014)

http://www.turkcebilgi.com/ansiklopedi/ regaib kandili (16.05.2014)

http://samil.ihya.org/ansiklopedi/mirac.html (16.05.2014)

http://www.turkcebilgi.com/Rehber Ansiklopedisi (17.05.2014)

http://www.fizan.net/berat-gecesi.html. Diyanet İslam Ansiklopedisi. (y.y.y) 5. Cilt, $475(12.05 .2014)$ 